\title{
Pengujian Karakteristik Turbin Angin Tipe Horizontal Sudu Flat Multiblade Dengan Pengaturan Sudut Sudu
}

\author{
Syafriyudin ${ }^{1}$, M. Suyanto ${ }^{2}$, Subandi ${ }^{3}$, M. Nurkhakim $\mathrm{W}^{4}$ \\ 1,2,3,4 Jurusan Teknik Elektro, Institut Sains dan Teknologi AKPRIND Yogyakarta \\ Coresponden author: dien@akprind.ac.id ${ }^{1}$, myanto@akprind.ac.id ${ }^{2}$, subandi@akprind.ac.id ${ }^{3}$, mnurkhakimw@gmail.com ${ }^{4}$
}

\begin{abstract}
Abstrak. Salah satu upaya untuk mengatasi krisis energy adalah dengan cara memanfaatkan energy angin sebagai sumber listrik. Pembangkit listrik tenaga angina merupakan suatu metode untuk membangkitkan energi listrik dengan cara memutar turbin angina yang dihubungkan dengan generator, energy listrik yang dihasilkan oleh generator disimpan dalam elemen penyimpan energy listrik (baterai). Yang selanjutnya akan dialirkan kepusat beban seperti rumah tangga. Perarancangan turbin angin tipe horizontal sudu flat multiblade dengan menggunakan mikrokontroller yang dapat mengubah sudut sudu sesuai kecepatan angin sehingga dapat memaksimalkan daya dari energi potensial angin. Untuk pengaturan sudut sudu yang dapat menyesuaikan kecepatan angin, menggunakan dua servo motor yang telah diberika control oleh arduinouno dari input anemometer sehingga sudut sudu dapat menyesuaikan kecepatan angin. Hasil yang didapat menunjukkan bahwa pengaturan sudut sudu pada turbin dapat meningkatkan putaran turbin angin, sehingga dapat menaikkan tegangan yang dibangkitkan pada generator. Sudut sudu yang optimal terdapat pada sudut $15^{\circ}$, pada kecepatan angin $9,5 \mathrm{~m} / \mathrm{s}$, yang menghasilkan putaran turbin sebesar $610 \mathrm{rpm}$.
\end{abstract}

Kata Kunci: EBT, turbin angin, Arduino, pengatur sudut sudu.

\begin{abstract}
One effort to overcome the energy crisis is to utilize wind energy as a power source. Angina power Plant is a method for generating electrical energy by rotating the angina turbine connected with the generator, the electric energy produced by the generator is stored in an element of electric energy storage (battery). The next one will be channeled to load center like household. The Perarancangan of the horizontal type flat Multiblade Sudu is using a microcontroller that can change the angle of the sudu according to the wind speed so as to maximize the power of wind potential energy. For a sudu angle setting that can adjust the speed of the wind, use two servo motors that have been control by the Arduinouno from the input anemometer so that the angle of the sudu can adjust the wind speed. The results have shown that the turbine-angle arrangement of the turbines can increase the rotation of the wind turbine, thereby increasing the voltage raised in the generator. The optimal angle of the Sudu is at a 150 angle, at a wind speed of $9.5 \mathrm{~m} / \mathrm{s}$, resulting in a turbine round of $610 \mathrm{rpm}$.
\end{abstract}

Keywords: EBT, wind turbine, Arduino, Sudu angle regulator.

\section{PENDAHULUAN}

Indonesia menargetkan peningkatan penggunaan energi terbarukan sebagaimana tertulis pada Peraturan Pemerintah nomor 79 tahun 2014. Pemerintah menargetkan porsi energi terbarukan sebesar $23 \%$ pada tahun 2025 dan $31 \%$ pada tahun 2050, guna menuju ketahanan energi di masa depan. Mengeksplorasi berbagai potensi energi terbarukan pada setiap wilayah di Indonesia merupakan cara yang tepat untuk mencapai target tersebut.

Tabel.1. Target pembanguna pembangkit EBT [3]

\begin{tabular}{|l|c|c|}
\hline Jenis Pembangkit & Target 2025 (MW) & Target 2050 (MW) \\
\hline Panas Bumi & 7.241 & 17.546 \\
\hline Air \& Mikrohidro & 20.960 & 45.379 \\
\hline Bioenergi & 5.532 & 26.123 \\
\hline Surya & 6.379 & 45.000 \\
\hline Angin & 1.807 & 28.607 \\
\hline EBT Lainnya & 3.128 & 6.383 \\
\hline
\end{tabular}

Sumber iesr 2017.
Dalam skala global berdasarkan data dari International Energy Agency (IEA) pola konsumsi energi dunia mengalami perubahan. Penggunaan energi primer konservatif seperti bahan bakar minyak, gas dan batubara tetap meningkat seiring dengan pertambahan jumlah penduduk dan aktifitas ekonomi namun ke depan diperkirakan pertumbuhan konsumsi energi fosil tersebut akan melambat. Disisi lain kenaikan luar biasa dari pemakaian energi terbarukan yang akan meningkat dua kali lipat dalam kurun waktu 10-15 tahun yang akan datang [5]. Perkiraan ini sangat mungkin terjadi dengan semakin sadarnya manusia untuk penggunaanGreen energy. Perkembanganteknologi saat ini juga turut mendukung pertumbuhan penggunaan berbagai potensi energi terbarukan.

Penggunaan turbin tipe horizontal sudu flat multiblade memanfaatkan arduino sebagai mikrokontroler arduino dan servo motor sebagai aktuator atau penggeraknya untuk mengatur besar plan area sesuai kondisi kecepatan angin.[4],Solar tree adalah Pembangkit Listrik Tenaga Surya yang menggabungkan panel surya dengan konstruksi seperti pohon, dengan desain pohon surya dapat menangkap intensitas sinar matahari yang lebih besar, baik di pagi hari, siang hari, 
dan sore hari.[14], Turbin angin jenis HAWT dan VAWT, mempunyai kelebihan dan kekurangan yang tergantung pada kecepatan angin dan tempatnya.Turbin angin sumbu horizontal dengan bilah baling-baling adalah yang paling umum, karena efisiensinya sekitar $60 \%$.[8],turbin angin memiliki dinamika nonlinear, kekuatan penggerak stokastik dan tidak terkendali sebagai input dalam bentuk kecepatan angin, Metode kontrol yang sesuai dapat memberikan optimisasi berkelanjutan [13]

Dengan menaikkan batas kecepatan flutter yang mengontrol gerakan aileron dengan fuzzy logic. Dengan menganalisis kecepatan flutter menggunakan metode-p, maka dapat diketahui batas kecepatan flutter, dan dengan control LQG dan fuzzy logic maka fenomena flutter dapat teratasi [2], model sistem pembangkit listrik dengan sel surya untuk rumah menggunakan panel jenis polikristalin mampu bekerja maksimum pada pukul 10.00 hingga 13.00 wib pada tegangan 17,5 volt [11]

\section{Potensi Energi Angin}

Energi angin di negara tropis pada umumnya memiliki kecepatan yang cukup rendah. Kecepatan angin rata-rata di Indonesia hanya sekitar 3-5 m/s. Hanya sedikit daerah di Indonesia yang memiliki kecepatan angin cukup besar. Potensi tenaga angin di Indonesia diperkirakan hanya sekitar 9.200 MW. [3].

Kajian potensi energy angin yang dapat dimanfaatkan sebagai pembangkit listrik tenaga angin di kota jambi menunjukkan Kecepatan angin rata-rata dalam setahun pada ketinggian diatas 2 meter adalah sebesar $2,45 \mathrm{~m} / \mathrm{s}$. dimana kecepatan angin tersebut masuk dalam kategori angin kelas 3 (tiga) yang masih dapat dimanfaatkan potensinya. [7]

\section{METODE}

Metode yang digunakan adalah metode eksperimen. Dengan membuat prototipe turbin angin tipe horizontal sudu flat multiblade yang sudut sudu nya diatur menggunakan Arduino, pengujian alat di lakukan di laboratorium konversi energy, dengan menggunakan wind tunnel sebagai simulasi untuk mendapatkan variable kecepatan angin.

Desain aero-struktural termasuk pertimbangan awal blade turbin angin kecil. Dengan sudu berongga mempercepat start pada kecepatan rendah dengan mengurangi inersia sudu,[1],Rangkaian Daya Buck Converter ripple mengahasilkan siklus kerja yang lebih halus dengan mengatur siklus kerja pengaturan frekuensi PWM dalam 1,7 Khz dan 3,3 Khz. [6]

\section{Perancangan Sistem}

Desain turbin angin yang mampu beroperasi pada berbagai kecepatan angin dan dapat diwujudkan dengan membuat plan area sudu yang berubah-ubah secara otomatis. Saat kecepatan angin rendah plan area berkurang dan saat kecepatan angin tinggi plan area bertambah. Pada penelitian ini telah dibuat turbin angin tipe horizontal sudu flat multiblade dengan pengaturan sudut sudu otomatis seperti pada Gambar
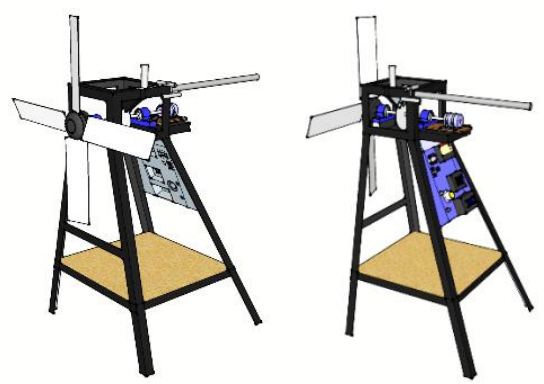

Gambar 1. Desain kincir angina

Perubahan pada plan area sudu turbin dilakukan dengan mengatur sudut pitch pada sudu dimana saat plan area bertambah sudut pitch sudu besar sedangkan saat plan area berkurang sudut pitch sudu kecil Diagram blok sistem pada rancang bangun turbin angin tipe horizontal sudu flat multiblade dengan pengaturan sudut sudu otomatis.

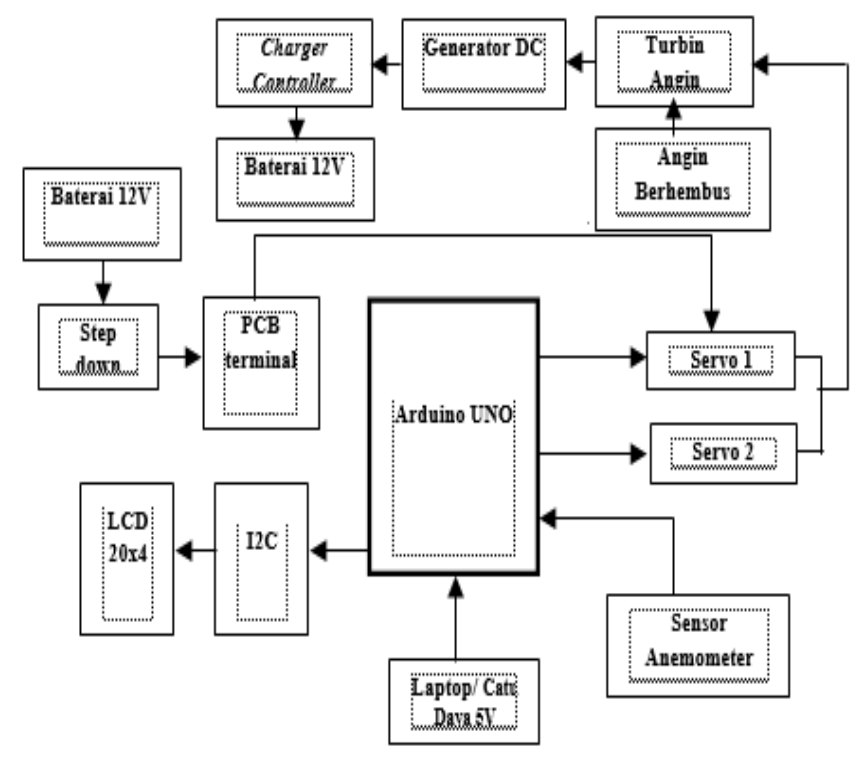

Gambar 2. Diagram Blok Sistem

Secara umum, rancangan dibagi menjadi 3 bagian yaitu bagian input, bagian kendali dan bagian output kendali. Bagian input terdiri dari generator DC yang diputar oleh turbin angin dimana generator terhubung dengan charger controller yang berfungsi untuk kontrol pengisian baterai. Bagian kontrol terdiri dari arduino untuk pemrosesan perintah dan kendali, arduino dan LCD disuplai catu daya 5V/ laptop, dengan LCD sebagai penampil kecepatan angin, input analog dari arduino adalah sensor anemometer sebagai perintah untuk memberikan bagian output kendali terhadap 2 servo terhadap sudu turbin. 


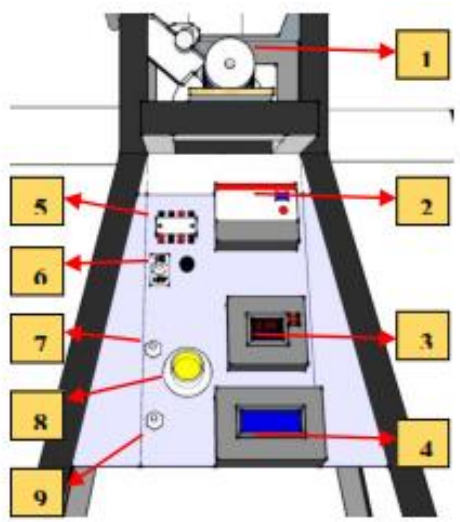

Gambar 3 Bagian rancangan kincir angina

Desain bagian panel belakang terdiri dari beberapa bagian. Pada Gambar 4 bagian- bagian panel belakang adalah sebagai berikut:

1 Generator DC

2 Charger Control

3 Voltmeter dan amperemeter

4 Penampil kecepatan

5 termnal

6 Saklar panel dan fuse

7 Saklar lampu

8 Fitting lampu

9 Saklar anemometer

\section{Sudu Turbin Angin}

Sumber penggerak dari generator menggunakan sumber energy angin dan berdasar hasil pengujian bahwa Efisiensi generator maksimum 20,68 \% dan minimum $3.10 \%$, [12]. Dengan kinerja aerodinamis Turbin Angin Sumbu Horisontal (HAWT) pada bilah sapuan maju dan mundur ditemukan bahwa bilah sapuan maju memiliki kemampuan untuk meningkatkan kinerja sedangkan bilah sapuan mundur cenderung mengurangi koefisien dorong [9].

Sudu turbin angin dibuat dari 4 lembar plat besi yang memiliki sifat ringan, kuat, dan mudah dibentuk. Profil sudu berbentuk persegi panjang dengan panjang $400 \mathrm{~mm}$, lebar $100 \mathrm{~mm}$ dan tebal plat $2 \mathrm{~mm}$. Diameter sapuan sudu turbin sebesar $980 \mathrm{~mm}$ seperti yang terlihat pada Gambar 4

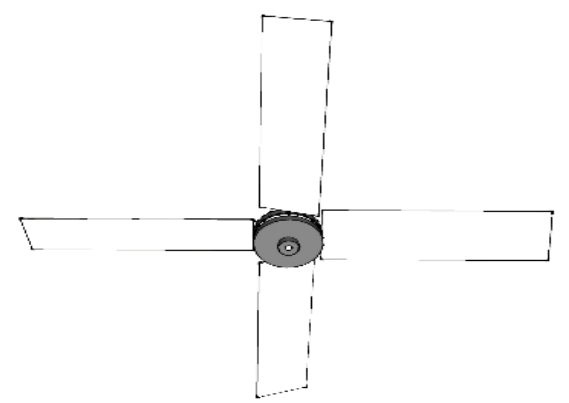

Gambar 4. Sudu dan Hub Sudu

\section{Kontrol Sudu}

Data hasil pengolahan yang telah diubah menjadi grafik selanjutnya akan diinput kedalam program kontrol dimana setiap kecepatan angin hanya diambil satu sudut dengan kurva tertinggi.

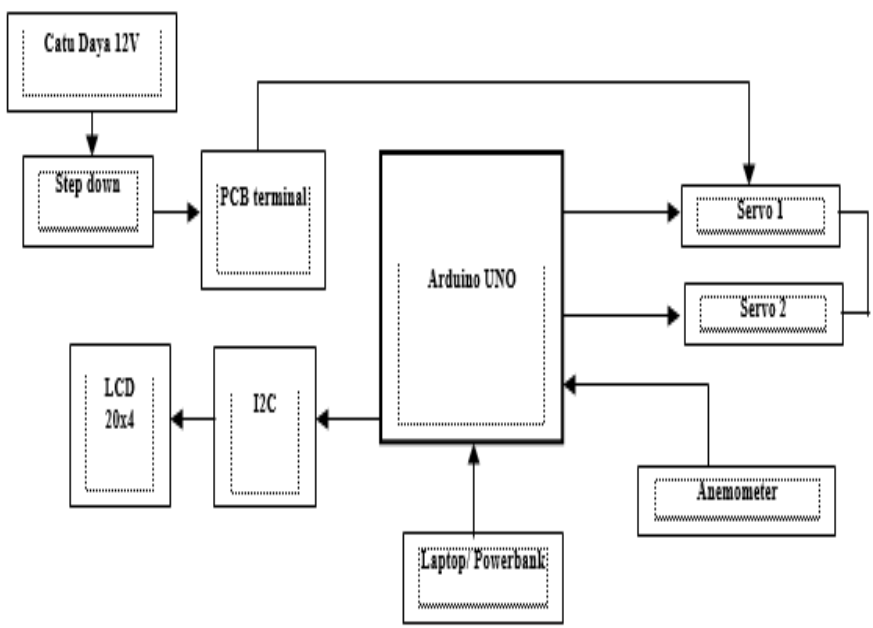

Gambar 5. Diagram Blok Kontrol Turbin

Sistem menggunakan sumber DC 12 volt dari baterai, setelah itu di step down menjadi 5 volt. Sumber ini digunakan untuk mensuplai dua servo melalui PCB terminal. Sedangkan arduino, LCD 4 x 20 dan sumber dari sensor kecepatan angin / anemometer disuplai dari laptop/powerbank menggunakan USB downloader. Untuk penggunaan pin data, sensor kecepatan angin pada pin 2, servomotor 1 pada pin 8 dan servomotor 2 pada pin 9, dan juga dengan penggunaan pin analog untuk LCD yakni SDA pada A5 dan SCL pada A4. Berdasarkan proses diagram tersebut, maka dapat digambarkan blok diagram dengan sistem close loop seperti Gambar 6.

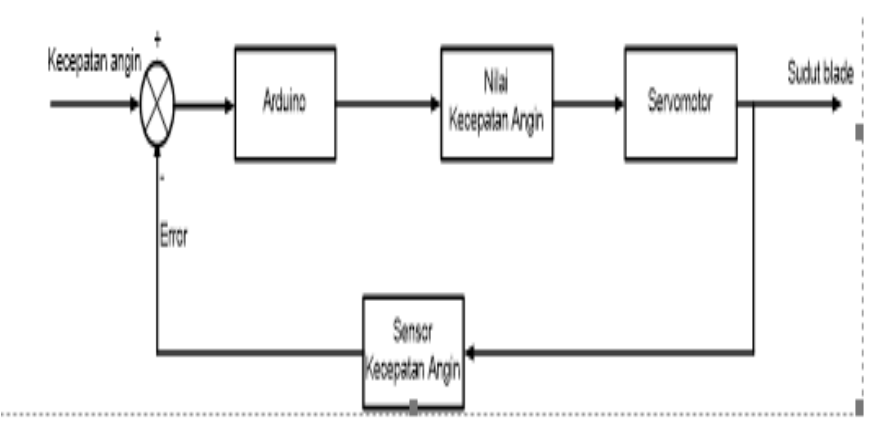

Gambar 6, Diagram Blok Pengaturan

Pergerakan sudu dimaksudkan agar didapatkan sudut terbaik pada kecepatan angin tertentu. Mekanisme ditunjukkan seperti pada Gambar 7, pergerakan ini menggunakan dua servomotor (nomor 2) sebagai penggerak utamanya. Pergerakannya menggunakan lengan dari servomotor (nomor 3) untuk mendorong hub (nomor 1) agar engsel merubah sudut sudu. Pada saat turbin berputar maka akan terjadi gesekan, pada saat berputar lengan servo akan bergesekan langsung dengan hub seperti yang ditunjukan (nomor 4). 


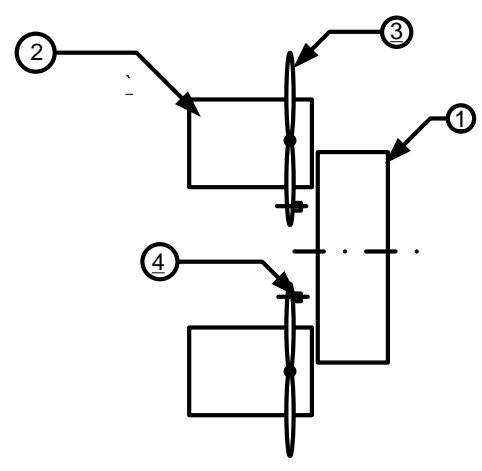

Gambar 7. Mekanisme perubahan sudut sudu

\section{Pengujian wind tunnel}

Pengujian yang dilakukan di dalam laboratorium, dimana turbin angin dihadapkan dengan windtunnel secara langsung seperti pada Gambar 8. Pengujian ini dimaksud untuk mendapatkan variabel kecepatan angin yang dapat diatur. data ini untuk mendapatkan karakteristik kecepatan angin terhadap keluaran tegangan minimal dan maksimal untuk setiap sudut yang akan digunakan sebagai acuan data input untuk panel kontrol.
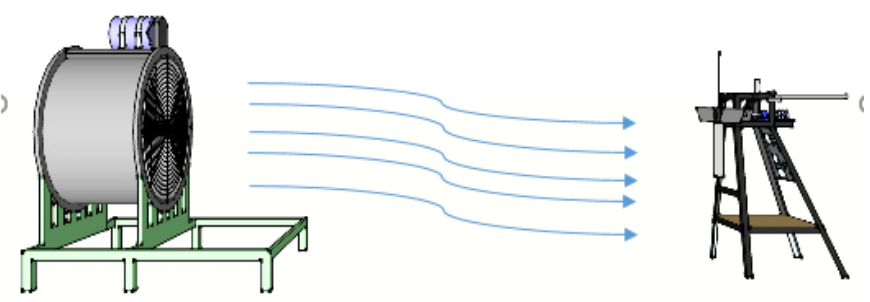

Gambar 8. Pengujian dengan wind tunnel

\section{Pengujian pengukuran Tegangan dan Arus}

Pada pengujian ini dilakukan dengan menambah variasi kecepatan angin mulai dari $1 \mathrm{~m} / \mathrm{s}$ sampai dengan $10 \mathrm{~m} / \mathrm{s}$. Untuk variable sudut blade yang digunakan yaitu sudut blade $15^{\circ}, 20^{\circ}, 25^{\circ}, 30^{\circ}, 35^{\circ}$ dan $40^{\circ}$. Data yang diambil adalah tegangan generator (VDC) sebelum masuk ke charger control, tegangan (VDC) dan arus (IDC) masuk ke beban (akumulator) melalui charger control. Selain itu juga data lain yang diambil adalah rpm rotor turbin tak berbeban, rpm rotor turbin berbeban.

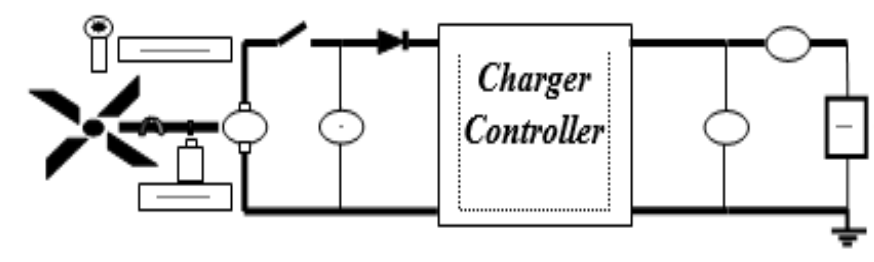

Gambar. 9. Rangkaian Pengujian Rekayasa

\section{Analisis Pengujian Tegangan dan Arus Terhadap Kecepatan Angin}

Pada analisis pengujian tegangan dan arus terhadap kecepatan angin dilakukan untuk mengetahui tegangan dan arus keluaran generator yang digunakan berdasarkan kecepatan angin. Pada pengujian ini, generator dihubungkan secara langsung menggunakan flexible coupling terhadap rotor turbin angin yang digunakan, output tegangan yang optimal digunakan untuk menginput sensor kontrol untuk menggerakkan sudu turbin. Pada saat mengukur kecepatan angin, diukur menggunakan alat anemometer, sedangkan putaran turbin / generator diukur menggunakan tachometer. Setelah generator berputar, maka tegangan dan arus output generator diukur menggunakan voltmeter dan amperemeter.

\section{Analisis Uji Kinerja Turbin Angin Flat Multiblade dengan kontrol}

Uji kinerja alat dilakukan dimana alat kontrol otomatis yang telah dirancang akan mengendalikan seluruh kinerja sistem secara otomatis. Pengendalian sudut sudu turbin dilakukan berdasarkan nilai tegangan optimal. Seluruh rangkaian dari sensor hingga aktuator dihubungkan ke mikrokontroler. Data yang terbaca akan ditampilkan ke display LCD $4 \times 20$, untuk menjadi feedback elements pada sistem. Nilai kinerja didapatkan dari pengujian kinerja alat dimana pengujian dilakukan dengan penerapan alat untuk mengetahui apakah alat yang dibuat mampu bekerja sesuai dengan yang diharapkan. Penerapan alat ini dimaksudkan mampu memberikan aksi-aksi dari komponen aktuator. Uji kinerja terbagi menjadi 2, yakni kinerja sensor anemometer dan kinerja aktuator.

\section{Analisis Perhitungan Efisiensi Generator}

Pada perhitungan ini yang menjadi parameter analisis adalah daya kinetik dari turbin dan daya output dari generator, setelah mendapatkan kedua nilai tersebut lalu dapat dihitung efisiensi generator dalam persentase.

\section{Data Hasil Tegangan dan Arus}

Proses pelaksanaan pengujian wind turbin di laboratorium dengan menggunakan wind tunnel, Data hasil pengujian diperoleh dan telah dilakukan di Laboratorium Konversi Energi seperti pada gambar 10

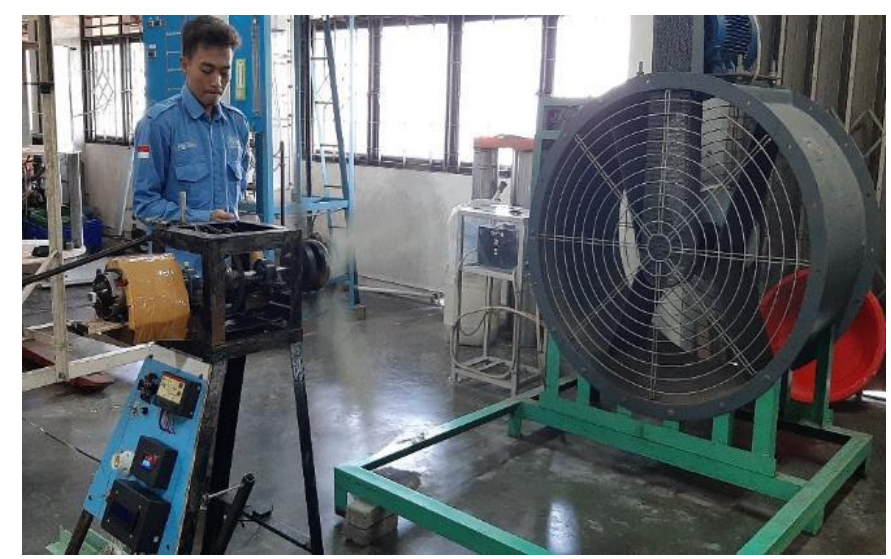

Gambar 10. Pengujian laboratorium menggunakan wind turbin 
Pada pengujian laboratorium, variasi sudut pitch pada sudu sebesar $15^{\circ}, 20^{\circ}, 25^{\circ}, 30^{\circ}, 35^{\circ}, 40^{\circ}$ dengan kecepatan angin mulai dari $1 \mathrm{~m} / \mathrm{s}$ sampai dengan 10 $\mathrm{m} / \mathrm{s}$. Beban yang digunakan dalam pengujian adalah akumulator kering jenis MF (Maintenance Free) GT6A (GM5Z-3B) berkapasitas 5 Ah dimana ketika pengujian, akumulator dikosongi terlebih dahulu sampai 11,5 Volt. Salah satu data hasil pengujian dapat dilihat pada Tabel 2. Data yang diambil merupakan data yang dibutuhkan dalam menganalisis kinerja turbin angin. Data tersebut antara lain kecepatan angin, putaran poros, tegangan dan arus generator.

Tabel 2. Data Hasil Pengujian Rekayasa Pada Turbin Angin Sudut $15^{\circ}$

\begin{tabular}{|c|c|c|c|c|c|c|}
\hline No & $\begin{array}{l}\text { Kecepatan angin } \\
\qquad(\mathrm{m} / \mathrm{s})\end{array}$ & $\begin{array}{c}\text { Kecepatan putar } \\
\text { turbin } \\
\text { (no load) (RPM) }\end{array}$ & $\begin{array}{l}\text { Kecepatan putar } \\
\text { turbin (load) (RPM) }\end{array}$ & $\begin{array}{c}\text { Tegangan DC } \\
\text { (no load) } \\
\text { (Volt) }\end{array}$ & $\begin{array}{l}\text { Tegangan DC } \\
\text { (load) (Volt) }\end{array}$ & $\begin{array}{c}\text { Arus DC } \\
\text { Charger } \\
\text { Controller }(\mathrm{A})\end{array}$ \\
\hline 1 & 1 & 0 & 0 & 0 & 0 & 0 \\
\hline 2 & 2 & 0 & 0 & 0 & 0 & 0 \\
\hline 3 & 3 & 0 & 0 & 0 & 0 & 0 \\
\hline 4 & 3,94 & 173,5 & 173,5 & 8,02 & 8,02 & 0 \\
\hline 5 & 5,04 & 210 & 206,1 & 10,7 & 10,4 & 0 \\
\hline 6 & 5,9 & 282,1 & 228,3 & 12,7 & 11,4 & 0,01 \\
\hline 7 & 7,16 & 428,9 & 257 & 17,6 & 12,4 & 0,38 \\
\hline 8 & 8,11 & 474 & 395,6 & 24 & 12,4 & 0,64 \\
\hline 9 & 8,7 & 575 & 410 & 24,8 & 12,4 & 0,75 \\
\hline 10 & 9,5 & 610 & 460 & 25,5 & 12,4 & 1,01 \\
\hline
\end{tabular}

Dari Tabel diatas dibuat grafik karakteristik sudut $15^{\circ}$ pengujian rekayasa hubungan antara kecepatan angin dengan putaran generator dan kecepatan angin dengan tegangan.

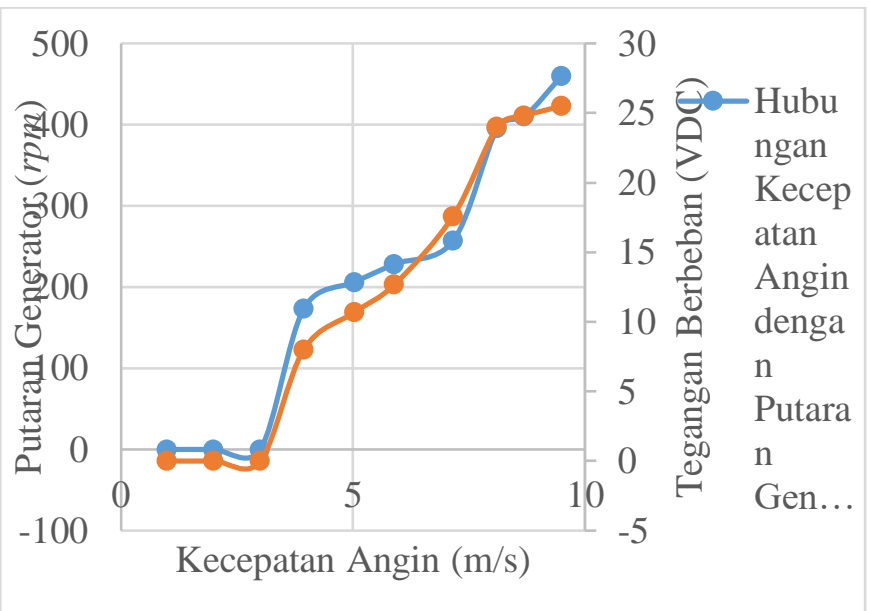

Gambar. 11 Kurva Karakteristik Sudut 15

Gambar 11 merupakan kurva karakteristik sudut $15^{\circ}$ pengujian rekayasa. Terdapat dua kurva dalam grafik tersebut yakni hubungan antara kecepatan angin dengan putaran generator dan hubungan kecepatan angin dengan tegangan. Setelah ditampilkan dalam bentuk grafik, dapat dilihat bahwa semakin tinggi kecepatan angin, semakin besar putaran yang dihasilkan rotor generator. Hal ini bisa dilihat pada trendline hubungan antara kecepatan angin dengan putaran generator.

Mengacu pada trendline kurva dari hubungan kecepatan angin dengan tegangan, turbin angin mampu menghasilkan tegangan minimal sebesar 8,02 volt pada kecepatan angin $3,94 \mathrm{~m} / \mathrm{s}$ dengan putaran turbin sebesar 206,1 rpm dan tegangan maksimal sebesar 25,5 volt pada kecepatan angin $9,5 \mathrm{~m} / \mathrm{s}$ dengan putaran turbin sebesar 610 rpm.Karakteristik Tegangan Generator
Turbin Angin Tipe Horizontal Sudu Flat Multiblade pada Pengujian laboratorium.

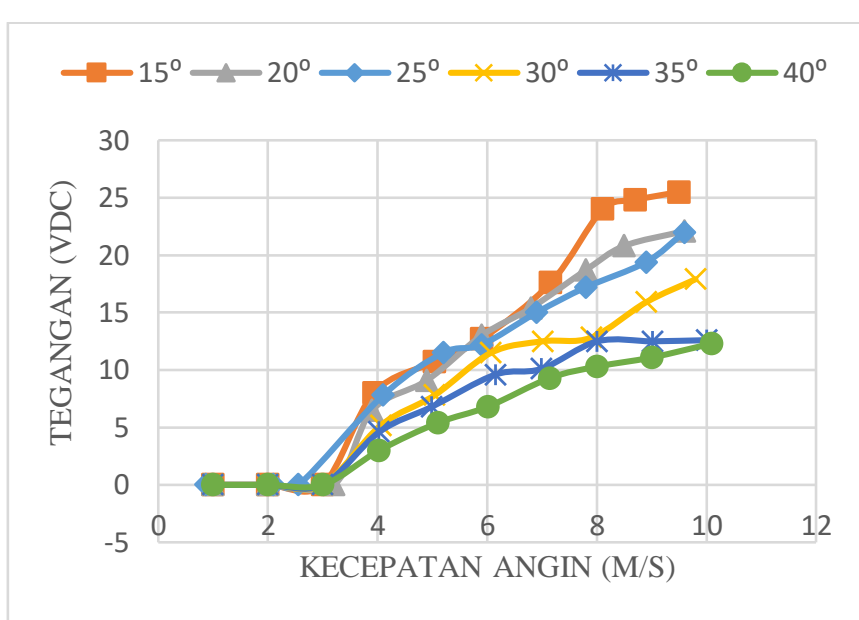

Gambar. 12 Grafik Hubungan Antara Tegangan dengan Kecepatan Angin

Gambar 12 merupakan grafik karakteristik hubungan antara kecepatan angin dengan tegangan pada pengujian rekayasa. Terdapat enam kurva dalam grafik tersebut yang terdiri dari sudut $15^{\circ}, 20^{\circ}, 25^{\circ}, 30^{\circ}, 35^{\circ}$, $40^{\circ}$. Pengujian kinerja diawali dengan kecepatan angin mulai dari $1 \mathrm{~m} / \mathrm{s}$ sampai dengan $10 \mathrm{~m} / \mathrm{s}$. Setelah ditampilkan dalam bentuk grafik, dapat dilihat bahwa kecepatan angin minimal untuk menghasilkan tegangan adalah $4 \mathrm{~m} / \mathrm{spada}$ setiap sudut dimana semakin tinggi kecepatan angin, semakin besar tegangan yang dihasilkan oleh generator. Hal ini membuktikan bahwa kecepatan angin berbanding lurus dengan tegangan listrik yang dihasilkan oleh generator. Berdasarkan Tabel 4.1 bahwa kecepatan angin yang berhembus mulai dari 1 $\mathrm{m} / \mathrm{s}$ sampai dengan $10 \mathrm{~m} / \mathrm{s}$ pada hubungan antara kecepatan angin dengan putaran generator juga berbanding lurus artinya ketika laju angin meningkat 
maka kecepatan putar dari turbin juga meningkat, yang mana hal itu akan menghasilkan energi yang besar.

Mengacu pada garis trenkurva dari masing-masing sudut tersebut, turbin angin flat multiblade dapat menghasilkan tegangan paling besar pada sudut $15^{\circ}$ sebesar 25,5 Volt pada kecepatan angin 9,5 m/sdengan putaran turbin sebesar $610 \mathrm{rpm}$ dan tegangan paling kecil pada sudut $40^{\circ}$ sebesar 3 volt pada kecepatan angin $4,03 \mathrm{~m} / \mathrm{s}$ dengan putaran turbin 77,7 rpm.

\section{Karakteristik Arus Generator Turbin Angin Tipe Horizontal Sudu Flat Multiblade}

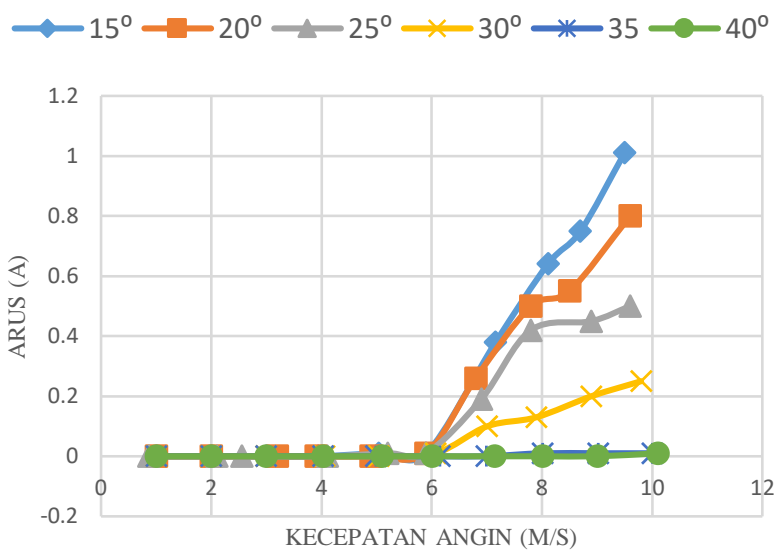

Gambar 13. Grafik Hubungan Antara Arus dengan Kecepatan Angin

Gambar 13 merupakan grafik karakteristik hubungan antara kecepatan angin dengan arus. Terdapat enam kurva dalam grafik tersebut yang terdiri dari sudut $15^{\circ}, 20^{\circ}, 25^{\circ}, 30^{\circ}, 35^{\circ}, 40^{\circ}$. Pengujian kinerja diawali dengan kecepatan angin mulai dari $1 \mathrm{~m} / \mathrm{s}$ sampai dengan $10 \mathrm{~m} / \mathrm{s}$.Beban yang digunakan dalam pengujian adalah akumulator kering jenis MF (Maintenance Free) GT6A (GM5Z-3B) berkapasitas 5 Ah dimana ketika pengujian, akumulator terlebih dahulu dikosongi hingga 11,5 Volt dan digunakan sebagai beban. Dalam pengisian akumulator, output tegangan dan arus pada generator idealnya adalah dengan tegangan 12,5 volt dan arus minimal 0,5 ampere pada beban yang digunakan.

Turbin angin mulai dapat mengeluarkan arus ideal pada sudut sudu $15^{\circ}$ sebesar 0,64 ampere pada kecepatan $8,11 \mathrm{~m} / \mathrm{s}$, pada sudut sudu $20^{\circ}$ sebesar 0,5 ampere pada kecepatan $7,8 \mathrm{~m} / \mathrm{s}$, dan pada sudut sudu $25^{\circ}$ sebesar 0,5 ampere pada kecepatan 9,6 $\mathrm{m} / \mathrm{s}$. Dari Gambar 12, terlihat bahwa kecepatan angin sangat berpengaruh terhadap putaran dari turbin angin yang mana akan mempengaruhi laju dari generator itu sendiri. Jika kecepatan angin semakin tinggi, maka semakin besar arus listrik yang dihasilkan generator. Hal ini membuktikan bahwa kecepatan angin berbanding lurus dengan arus listrik yang dihasilkan oleh generator.

Mengacu pada trendline kurva dari masingmasing sudut tersebut, turbin angin flat multiblade dapat menghasilkan arus paling besar pada sudut $15^{\circ}$ sebesar 1,01 A pada kecepatan angin 9,5 $\mathrm{m} / \mathrm{s}$. Dalam menentukan parameter ideal dari tegangan dan arus yang sudah dibuat grafik dari pengujian rekayasa maka penulis melakukan pengujian langsung di alam agar dapat mempertimbangkan penyesuaian sudut pada mikrokontroler.

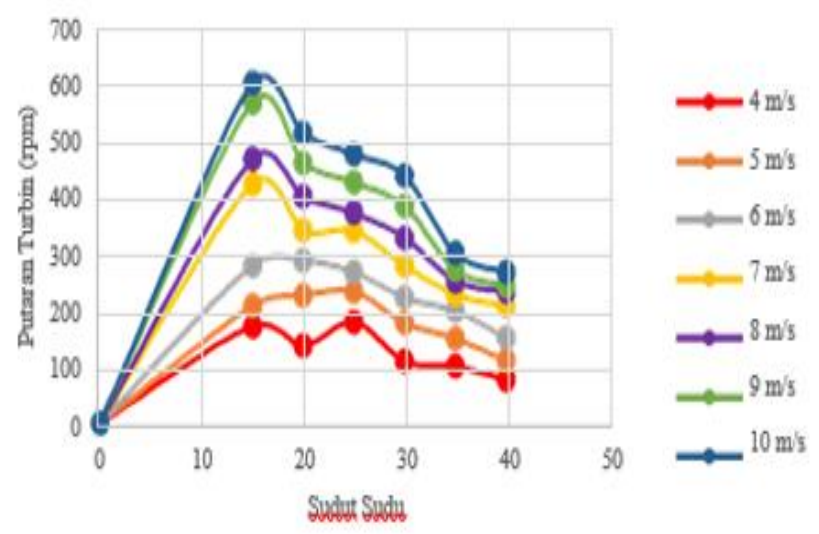

Gambar 14. Grafik hubungan antara sudut sudu denganputaran turbin

\section{SIMPULAN}

Berdasarkan hasil pengujian dan uji kinerja, maka dapat diperoleh kesimpulan sebagai berikut:

1. Pengujian yang dilakukan laboratorium, turbin angin flat multiblade dapat menghasilkan tegangan paling besar pada sudut $15^{\circ}$ sebesar 25,5 Volt pada kecepatan angin $9,5 \mathrm{~m} / \mathrm{s}$ dengan putaran turbin $610 \mathrm{rpm}$ dan turbin angin flat multiblade dapat menghasilkan arus paling besar pada sudut $15^{\circ}$ sebesar 1,01 A pada kecepatan angin $9,5 \mathrm{~m} / \mathrm{s}$ dengan putaran turbin 460 rpm

2. turbin angin tipe horizontal sudu flat multiblade dengan menggunakan mikrokontroller arduino UNO sebagai pengaturan sudut sudu secara otomatis

3. Perubahan sudut sudu yang diatur secara otomatis dapat meningkatkan menaikkan tegangan yang dihasilkan oleh generator.

4. Semakin tinggi sudut sudu yang di gunakan maka dibutuhkan kecepatan angin yang besar untuk dapat memutar turbin.

\section{DAFTAR PUSTAKA}

[1] Abolfazl Pourrajabian, Peyman Amir, Nazmi Afshar, Mehdi Ahmadizadeh, David Wood, 2015, Aero-structuraldesignandoptimization ofasmallwindturbineblade, journal Elsevier Renewable Energy xxx 1-12

[2] Akhmad Fauzilhaq, Ismoyo Haryanto, 2016. Flutter Suppression Air foil Sudu Turbin Angin Menggunakan Lqg Controller Dan Fuzzy Logic, Jurnal Teknik Mesin S-1, Vol. 4, No. 2

[3] Ditjen EBTKE, 2016. Statistik Energi Baru Terbarukan dan Konservasi Energi Jakarta 
[4] Elsa Khunaifi, Rendi Pangestuningtyas, Tanti Heriawati, 2019., Smart WindTurbine Tipe Horizontal Sudu Datar Multiblade Dengan Menggunakan Arduino Sebagai Pengaturan Sudut Sudu Secara Otomatis, jurnal teknik Energi vol.15 no. 3

[5] Fontana, A., \& Zainal, A. (Ed.), 2016. 19 Tahun Inovasi Ketenagalistrikan Indonesia PLN Berinofasi untuk Indonesia. 1st ed. Jakarta: PLN Research Institute.

[6] Leily. W. Johar, 2018, Kajian kelayakan potensi energi angin untuk dimanfaatkan menjadi energi listrik disekitaran legok-kota jambi, Journal of Electrical Power Control and AutomationVol.1 No.1

[7] Magedi Moh. M.Saad, Norzelawati Asmuin, 2014, Comparison of Horizontal Axis Wind Turbinesand Vertical Axis Wind Turbines, IOSR Journal of Engineering (IOSRJEN) Vol.04, Issue 08 (August.2014), PP 27-30

[8] Mehmet Numan Kaya, Faruk Kose, Derek Ingham, Lin Ma, Mohamed pourkashanian 2018, Aerodynamic performance of a horizontal axis wind turbine with forward and backward swept blades, Journal of Wind Engineering \& Industrial Aerodynamics 176 (2018) 166-173

[9] Muhammad Faadhil, Karnowo, Samsudin Anis, 2018., Pengaruh sudut serang terhadap kinerja kincir angin Helix Gorlov dengan penambahan Curveplate, Jurnal Sains dan Teknologi (Sainteknol), Vol 16 No.1

[10] M. Suyanto, T Rusianto, Subandi, 2019, Development of A Household Solar Power Plant: System Using Solar Panels, OP Conf. Series: Materials Science and Engineering conference series 807 (2020) 01200

[11] Priyaningsih, N., Yuniarti, N.. 2017, Analisis Efesiensi generator pada wind turbine, jurnal edukasi elektro, vol 1 , no. 2

[12] Silvio Simani, 2015, Advance dissues of windturbine mode lingand Control, Journal of Physics: Conference Series 659 (2015) 012001

[13] Syafriyudin, 2018, Characteristic Solar Tree Construction on Solar panel Power Plant, International Conference on Science and Technology (ICST), Atlantis Highlights in Engineering (AHE) vo 1., pp 515-521 